\title{
Penerapan Metode Promethee II pada Penerimaan Dana Bantuan Masyarakat Kurang Mampu di Kantor Kepala Desa
}

\author{
Fany Than Ervina Sitanggang1, Eka Irawan², Widodo Saputra ${ }^{3}$, Riski Sundari \\ ${ }^{124}$ STIKOM Tunas Bangsa Pematangsiantar \\ ${ }^{3}$ AMIK Tunas Bangsa Pematangsiantar \\ Jln. Jend Sudirman Blok A No.1-3 Pematangsiantar, Sumatera Utara, Indonesia
}

fanyervina07@gmail.com

\begin{abstract}
Receipt of aid funds for economically disadvantaged people and those who are increasingly pressing their lives because of the increase in all prices of food or basic necessities. Invalid data causes mistakes in giving recipients of assistance to those who are entitled to receive it. Many occurrences state that the assistance often does not occur properly, it makes it difficult for the surveyors to select candidates for the funding. So the author conducted a study aimed at providing computerized alternative decisions at the Office of the Village Head. In the process of this research using the PROMETHEE II Method (Preference Ranking Organization Method for Enrichment Evaluation II) where this method describes and describes a solution in pairs between criteria one with other criteria and sub-criteria one and the other sub-criteria in PROMETHEE II (Preference Ranking Organization Method For Enrichment Evaluation II). The aim of the researcher is to propose to prioritize the receipt of aid funds so that they are right on target and can help people who are less able to make decisions. Based on the results of the analysis researchers can solve the problem in determining the receipt of aid funds to the community well in decision making.
\end{abstract}

Keywords: PROMETHEE II, Decision Support System, Village Head

Abstrak- Penerimaan dana bantuan bagi masyarakat tidak mampu secara ekonomi dan yang semakin menekan kehidupan mereka sebab akibatnya naiknya semua harga pangan atau kebutuhan pokok. Data yang tidak valid menyebabakan kesalahan pemberian penerima bantuan pada pihak yang berhak menerimanya. Banyak terjadinya yang menyatakan bahwa bantuan tersebut sering terjadi tidak tepat penerimaannya, hal tersebut menyulitkan bagi para survei dalam menyeleksi calon penerimaaan dana tersebut. Maka penulis melakukan penelitian yang bertujuan agar dapat memberikan alternatif keputusan yang berkomputerisasi pada Kantor Kepala Desa. Dalam proses penelitian ini menggunakan Metode PROMETHEE II (Preference Ranking Organization Method For Enrichment Evaluation II) yang dimana metode ini menjelaskan dan menggambarkan suatu penyelesaiannya dilakukan perbandingan berpasangan antara kriteria satu dengan kriteria yang lain serta subkriteria satu dan subkriteria yang lain dalam PROMETHEE II (Preference Ranking Organization Method For Enrichment Evaluation II). Tujuan peneliti memberikan usulan untuk prioritaskan penerimaan dana bantuan agar tepat sasaran dan dapat membantu masyarakat yang kurang mampu dalam pengambilan keputusan. Berdasarkan hasil analisis peneliti dapat menyelesaikan masalah dalam penentuan penerimaan dana bantuan kepada masyarakat dengan baik dalam pengambilan keputusan.

Kata Kunci : PROMETHEE II, Sistem Pendukung Keputusan, Kepala Desa.

\section{PENDAHULUAN}

Sistem Pendukung Keputusan Sistem pendukung keputusan adalah suatu sistem informasi spesifik yang ditujukan untuk membantu menejemen dalam mengambil keputusan yang berkaitan dengan persoalan yang bersifat semi terstruktur. Sistem pendukung keputusan merupakan Computer Based Information System (CBIS) yang interaktif, fleksibel, mudah disesuaikan (dapat beradaptasi) 
yang secara khusus dikembangkan untuk mendukung penyelesaian dari masalah yang tidak terstruktur untuk meningkatkan pembuatan keputusan [1]-[11]. PROMETHEE adalah satu dari beberapa metode penentuan urutan atau prioritas dalam analisis multikriteria. Metode ini dikenal sebagai metode yang efisien dan simple, tetapi juga yang mudah diterapkan dibanding dengan metode lain untuk menuntaskan masalah multikriteria. Metode ini mampu mengakomodir kriteria pemilihan yang bersifat kuantitatif dan kualitatif [12]. PROMETHEE merupakan salah satu dari metode Multi Criteria Decision Making (MCDM) yang berarti melakukan penentuan atau pengurutan dalam suatu analisis multikriteria, metode ini dikenal karena konsepnya yang efisien dan simple, selain ituuntuk menyelesaikan masalah yang berhubungan dengan multikriteria, metode ini juga sangat mudah untuk diterapkan daripada metode lainnya [13].Pemerintah membuat suatu program penerimaan bantuan bagi masyarakat yang kurang mampu dimana bantuan akan diberikan langsung kepada masyarakat kurang mampu sehingga membantu masyarakat untuk memenuhi biaya hidupnya.

Penyaluran bantuan ini harus dilakukan dengan baik, transparan dan terorganisir agar yang diberikan diterima oleh masyarakat kurang mampu yang benar-benar membutuhkan. Proses penilaian diserahkan kepada ketua RT setempat yang bersifat subyektif dan akan diseleksi lagi oleh tim dikecamatan. Beberapa penelitian tentang PROMETHEE II seperti Mesran dkk [14],Sistem Layanan dan Rujukan Terpadu (SLRT) adalah salah satu program yang dibuat oleh pemerintah yang bertujuan untuk mengidentifikasi kebutuhan masyarakat miskin. Dan penelitian lainnya oleh Siahaan et al., (2018)Perkebunan sangat berperan sebagai pendorong pengembangan wilayah juga sebagai pendorong pengembangan ekonomi kerakyatan. Salah satu tanaman perkebunan yang menduduki penting di Indonesia adalah kelapa sawit. Desa Rambung Merah merupakan salah satu desa di Kecamatan Siantar Kabupaten Simalungun, dimana dalam penyaluran dana bantuan masyarakat kurang mampu masih memiliki banyak kendala, seperti kurang tepatnya sasaran penerimaan bantuan kepada masyarakat kurang mampu, beberapa masyarakat yang layak menerima bantuan ternyata belum mendapatkan bantuan tersebut. Dengan mengacu pada masalah diatas, maka tujuan yang hendak dicapai dalam penelitian ini adalah menghasilkan Sistem Pendukung Keputusan Penerimaan Dana Bantuan Masyarakat Kurang Mampu di Kantor Kepala Desa Rambung Merah untuk membantu pemerintah setempat dalam menentukan penyaluran bantuan kepada masyarakat. Sistem Pendukung Keputusan ini diharapkan dapat membantu Kantor Kepala Desa dalam mengambil keputusan secara cepat, tepat, dan adil dalam menentukan penerima bantuan kepada masyarakat kurang mampu sehingga bantuan yang diberikan dapat sampai kepada masyarakat yang membutuhkan. Dari latar belakang diatas didapat suatu rumusan masalah yaitu bagaimana membuat penilaian penentuan calon Penerimaan Dana Bantuan Masyarakat Kurang Mampu yang hanya pada Huta I di Desa Rambung Merah dengan kriteria pekerjaan, pendapatan, jumlah tanggungan, status tempat tinggal, sumber air, dan kondisi rumah. 


\section{METODOLOGI PENELITIAN}

Metode penelitian digunakan sebagai pengumpulan data yang selanjutnya dalam pelaksanaan penelitian agar hasil yang dicapai tidak menyimpang dari tujuan yang telah dilakukan sebelumnya.

\subsection{Metode Pengumpulan Data}

Pada tahap ini dilakukan pengumpulan data yang dibutuhkan untuk membangun sistem penentuan calon penerimaan bantuan kepada masyarakat kurang mampu, yaitu:

1. Wawancara, Penulis mengumpulkan keterangan, data serta informasi yang akan berguna dalam pembuatan sistem pendukung keputusan dalam menentukan calon penerimaan bantuan kepada masyarakat kurang mampu.

2. Observasi, Penulis melakukan pengamatan langsung dengan cara melakukan peninjauan dan pencatatan langsung ke Kantor Kepala Desa setempat untuk memperoleh informasi yang diperlukan.

3. Studi Pustaka, Studi pustaka dilakukan dengan tujuan untuk mengetahui metode apa yang akan digunakan untuk menyelesaikan permasalahan yang akan diteliti, mempelajari buku-buku, artikel-artikel dan jurnal-jurnal yang berhubungan dengan permasalahan yang akan dibahas.

\subsection{Analisis dan Perancangan Sistem}

Pada perancangan sistem pendukung keputusan, analisa memegang peranan yang penting dalam membuat rincian sistem baru, berikut hasil analisis dan perancangan sistem.

\subsubsection{Analisa Permasalahan}

Berdasarkan hasil analisa yang dilakukan maka penulis bermaksud untuk membuat sebuah sebuah Sistem Pendukung Keputusan agar dapat membantu dan mendukung manajemen dalam penentuan calon mayarakat yang kurang mampu, sehingga diharapkan mampu mengatasi kesenjangan pertumbuhan perekonomian sekaligus membantu perekonimian masyarakat miskin.

\subsubsection{Perancangan Penelitian}

Perancangan penelitian menjelaskan tentang urutan alir sistem yang_terlebih dahulu dilakukan proses.

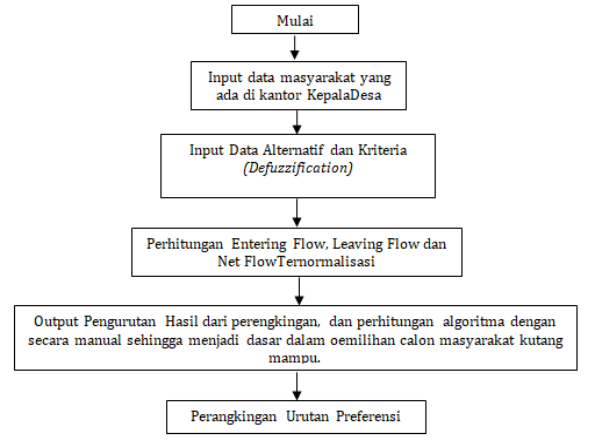

Gambar 1. Alur Perancangan Penelitian 


\subsubsection{Algoritma Sistem}

Pada algoritna sistem ini akan dijelaskan mengenai algoritma dari metode PROMETHEE II yang diterapkan pada sistem serta aturan-aturan yang dapat dilihat pada basis pengetahuan dan perhitungan manual dari metode yang digunakan. Data kriteria yang digunakan dalam penentuan penerimaan dana bantuan dilihat pada tabel 1. adalah sebagai berikut :

Tabel 1. Data Kriteria

\begin{tabular}{|c|c|c|c|c|c|}
\hline No & Kriteria & Nama Kriteria & Keterangan & Bobot & Tipe \\
\hline 1 & C1 & Pekerjaan & Pengangguran & \multirow[t]{4}{*}{20} & \multirow[t]{4}{*}{ Benefit } \\
\hline & & & Buruh & & \\
\hline & & & Wiraswasta & & \\
\hline & & & PNS & & \\
\hline 2 & $\mathrm{C} 2$ & Pendapatan & Rp.500.000; <=Rp.500.000; & \multirow[t]{4}{*}{20} & \multirow[t]{4}{*}{ Cost } \\
\hline & & & $>$ Rp.500.000; s/d Rp.1000.000 & & \\
\hline & & & $>$ Rp.1000.000; s/d Rp.1500.000 & & \\
\hline & & & Rp.2000.000 & & \\
\hline 3 & $\mathrm{C} 3$ & Jumlah Tanggungan & 4 anak atau lebih & \multirow[t]{4}{*}{10} & \multirow[t]{4}{*}{ Benefit } \\
\hline & & & 3 anak & & \\
\hline & & & 2 anak & & \\
\hline & & & 1 anak/tidak punya anak & & \\
\hline 4 & $\mathrm{C} 4$ & Status Tempat Tinggal & Rumah Sewa & \multirow[t]{3}{*}{15} & \multirow[t]{3}{*}{ Benefit } \\
\hline & & & Numpang dengan orang tua & & \\
\hline & & & Rumah milik sendiri & & \\
\hline 5 & $\mathrm{C} 6$ & Sumber Air & Air Sungai & \multirow[t]{4}{*}{15} & \multirow[t]{4}{*}{ Benefit } \\
\hline & & & Air Sumur & & \\
\hline & & & Numpang dengan tetangga & & \\
\hline & & & PDAM & & \\
\hline 6 & $\mathrm{C} 6$ & Kondisi Rumah & Sangat Sederhana & \multirow[t]{4}{*}{20} & \multirow[t]{4}{*}{ Benefit } \\
\hline & & & Sederhana & & \\
\hline & & & Cukup & & \\
\hline & & & Кауа & & \\
\hline
\end{tabular}

Dengan tingkat kepentingan sebagai berikut :

Tabel 2. Tingkat Kepentingan

\begin{tabular}{|c|l|}
\hline Bobot & Keterangan \\
\hline 4 & Sangat Layak \\
\hline 3 & Layak \\
\hline 2 & Cukup Layak \\
\hline 1 & Tidak Layak \\
\hline
\end{tabular}

Tabel 3. Menentukan Kriteria Pekerjaan

\begin{tabular}{|c|c|c|}
\hline Pekerjaan & Skor & Nilai \\
\hline Pengangguran & Sangat Layak & 4 \\
\hline Buruh & Layak & 3 \\
\hline Wiraswasta & Cukup & 2 \\
\hline PNS & Kurang & 1 \\
\hline
\end{tabular}


Tabel 4. Menentukan Kriteria Pendapatan

\begin{tabular}{|c|c|c|}
\hline Pendapatan & Skor & Nilai \\
\hline Rp.500.000; <=Rp.500.000; & Sangat Layak & 4 \\
\hline >Rp.500.000; s/d Rp.1000.000 & Layak & 3 \\
\hline >Rp.1000.000; s/d Rp.1500.000 & Cukup & 2 \\
\hline Rp.2000.000 & Kurang & 1 \\
\hline
\end{tabular}

Tabel 5. Menentukan Kriteria Jumlah Tanggungan

\begin{tabular}{|c|c|c|}
\hline Jumlah Tanggungan & Skor & Nilai \\
\hline 4 anak atau lebih & Sangat Layak & 4 \\
\hline 3 anak & Layak & 3 \\
\hline 2 anak & Cukup & 2 \\
\hline 1 anak/tidak punya anak & Kurang & 1 \\
\hline
\end{tabular}

Tabel 6. Menentukan Kriteria Sumber Air

\begin{tabular}{|l|l|l|}
\hline \multicolumn{1}{|c|}{ Sumber Air } & \multicolumn{1}{c|}{ Skor } & Nilai \\
\hline Air Sungai & Sangat Layak & 4 \\
\hline Air Sumur & Layak & 3 \\
\hline Numpang dengan tetanga & Cukup & 2 \\
\hline PDAM & Kurang & 1 \\
\hline
\end{tabular}

Tabel 7. Kriteria Kondisi Rumah

\begin{tabular}{|l|l|l|}
\hline Kondisi Rumah & Skor & Nilai \\
\hline Sangat Sederhana & Sangat Layak & 4 \\
\hline Sederhana & Layak & 3 \\
\hline Cukup & Cukup & 2 \\
\hline Kurang & Kurang & 1 \\
\hline
\end{tabular}

Tabel 8. Data Alternatif

\begin{tabular}{|l|l|l|}
\hline \multicolumn{1}{|c|}{ Alt } & J. Kelamin & \multicolumn{1}{c|}{ Alamaat } \\
\hline A1 & Laki-Laki & Jl.Rajamin Purba \\
\hline A2 & Laki-Laki & Jl.Makmur \\
\hline A3 & Laki-Laki & Jl.Makmur Ujung \\
\hline A4 & Perempuan & Jl.Makmur Ujung \\
\hline A5 & Laki-Laki & Jl.Makmur \\
\hline A6 & Laki-Laki & Jl.Cempaka \\
\hline A7 & Laki-Laki & Jl.H.Ulakma Sinaga \\
\hline A8 & Laki-Laki & Jl.Cempaka Atas \\
\hline A9 & Laki-Laki & Jl.Makmur \\
\hline A10 & Laki-Laki & Jl.Rajamin Purba \\
\hline A11 & Laki-Laki & Jl.Makmur \\
\hline A12 & Laki-Laki & Jl.Cempaka \\
\hline A13 & Laki-Laki & Jl.Makmur \\
\hline A14 & Laki-Laki & Jl.Cempaka \\
\hline A15 & Laki-Laki & Jl.Cempaka \\
\hline A16 & Laki-Laki & Jl.Cempaka \\
\hline A17 & Laki-Laki & Jl.Cempaka \\
\hline A18 & Laki-Laki & Jl.Rajamin Purba \\
\hline
\end{tabular}


Untuk menentukan altenatif dan kriteria peniliti telah melakukan wawancara langsung kepada masyarakat. Dalam penelitian ini ada delapan belas alternatif dan enam kriteria yaitu :

Tabel 9. Nilai Kriteria

\begin{tabular}{|l|c|c|c|c|c|c|}
\hline \multirow{2}{*}{ Alternatif } & \multicolumn{7}{|c|}{ Kriteria } \\
\cline { 2 - 7 } & C1 & C2 & C3 & C4 & C5 & C6 \\
\hline A1 & 4 & 4 & 3 & 4 & 2 & 4 \\
\hline A2 & 1 & 1 & 2 & 2 & 3 & 2 \\
\hline A3 & 2 & 3 & 3 & 4 & 3 & 3 \\
\hline A4 & 1 & 1 & 3 & 2 & 1 & 2 \\
\hline A5 & 1 & 1 & 4 & 2 & 1 & 1 \\
\hline A6 & 3 & 4 & 3 & 3 & 4 & 4 \\
\hline A7 & 1 & 1 & 2 & 2 & 1 & 2 \\
\hline A8 & 3 & 4 & 4 & 4 & 3 & 4 \\
\hline A9 & 3 & 4 & 4 & 4 & 3 & 4 \\
\hline A10 & 1 & 1 & 4 & 2 & 1 & 1 \\
\hline A11 & 3 & 4 & 4 & 4 & 1 & 4 \\
\hline A12 & 2 & 3 & 4 & 3 & 3 & 4 \\
\hline A13 & 3 & 4 & 4 & 3 & 4 & 4 \\
\hline A14 & 3 & 4 & 3 & 4 & 3 & 4 \\
\hline A15 & 3 & 3 & 3 & 3 & 1 & 3 \\
\hline A16 & 4 & 4 & 3 & 3 & 3 & 4 \\
\hline A17 & 3 & 3 & 4 & 4 & 3 & 4 \\
\hline A18 & 3 & 3 & 4 & 4 & 1 & 4 \\
\hline
\end{tabular}

Tabel 4 adalah alternatif yang telah diberikan nilai berdasarkan bobot kriteria yang telah ditentukan diatas. Tabel 3.4 adalah data yang masih merupakan skor dari penulis dengan ketentuan yang tercantum pada form penilaian yang diberikan oleh penulis bahwa nilai diperoleh dari Nilai $=\mathrm{W}$ (bobot) $\mathrm{x}$ Skor, sehingga hasil dapat dilihat pada tabel 5.

Tabel 10. Data Masyarakat Yang Telah Diolah

\begin{tabular}{|l|c|c|c|c|c|c|}
\hline \multirow{2}{*}{ Alternatif } & \multicolumn{7}{|c|}{ Kriteria } \\
\cline { 2 - 7 } & C1 & C2 & C3 & C4 & C5 & C6 \\
\hline A1 & 80 & 80 & 30 & 60 & 30 & 80 \\
\hline A2 & 20 & 20 & 20 & 30 & 45 & 40 \\
\hline A3 & 40 & 60 & 30 & 60 & 45 & 60 \\
\hline A4 & 20 & 20 & 30 & 30 & 15 & 40 \\
\hline A5 & 20 & 20 & 40 & 30 & 15 & 20 \\
\hline A6 & 60 & 80 & 30 & 45 & 60 & 80 \\
\hline A7 & 20 & 20 & 20 & 30 & 15 & 40 \\
\hline A8 & 60 & 80 & 40 & 60 & 45 & 80 \\
\hline A9 & 60 & 80 & 40 & 60 & 45 & 80 \\
\hline A10 & 20 & 20 & 40 & 30 & 15 & 20 \\
\hline A11 & 60 & 80 & 40 & 60 & 15 & 80 \\
\hline A12 & 40 & 60 & 40 & 45 & 45 & 80 \\
\hline A13 & 60 & 80 & 40 & 45 & 60 & 80 \\
\hline A14 & 60 & 80 & 30 & 60 & 45 & 80 \\
\hline A15 & 60 & 60 & 30 & 45 & 15 & 60 \\
\hline A16 & 80 & 80 & 30 & 45 & 45 & 80 \\
\hline A17 & 60 & 60 & 40 & 60 & 45 & 80 \\
\hline
\end{tabular}




\begin{tabular}{|l|c|c|c|c|c|c|}
\hline \multirow{2}{*}{ Alternatif } & \multicolumn{7}{|c|}{ Kriteria } \\
\cline { 2 - 7 } & C1 & C2 & C3 & C4 & C5 & C6 \\
\hline A18 & 60 & 60 & 40 & 60 & 15 & 80 \\
\hline
\end{tabular}

1. Kemudian membuat matriks normalisasi menggunakan persamaan (1) jika bernilai menguntungkan (benefit).

$R_{i j}=\frac{\left[x_{i j}-\min \left(x_{i j}\right)\right]}{\left[\max \left(x_{i j}\right)-\min \left(x_{i j}\right)\right]}$

$\mathrm{X}_{\mathrm{ij}}$ Max $=\{80,20,40,20,20,60,20,60,60,20,60,40,60,60,60,80,60,60\}$

$\mathrm{X}_{\mathrm{ij}} \mathrm{Max}=80$

$\mathrm{X}_{\mathrm{ij}}{ }^{\mathrm{Min}}=\{80,20,40,20,20,60,20,60,60,20,60,40,60,60,60,80,60,60\}$

$\mathrm{X}_{\mathrm{ij}} \operatorname{Min}=20$

$\mathrm{R}_{11}=\frac{[[80-20]]}{[[80-20]]}$

$\mathrm{R}_{11}=\frac{0}{0}=1$

$(\mathrm{i}=1,2, \ldots, \mathrm{n}: \mathrm{j}=1,2, \ldots, \mathrm{m})$... dimana Xij adalah ukuran kinerja dari alternatifnya sesuai kriteria jth. Untuk kriteria yang tidak menguntungkan (cost), rumus (1) dapat ditulis ulang sebagai berikut dengan menggunakan persamaan (2) jika bernilai $\operatorname{cost} C 2$ :

$R_{i j}=\frac{\left[\max \left(x_{i j}\right)-x_{i j}\right]}{\left[\max \left(x_{i j}\right)-\min \left(x_{i j}\right)\right]}$

$\mathrm{X}_{\mathrm{ij}}{ }^{\operatorname{Max}}=\{80,20,60,20,20,80,20,80,80,20,80,60,80,80,60,80,60,60\}$

$\mathrm{X}_{\mathrm{ij}} \mathrm{Max}=80$

$\mathrm{X}_{\mathrm{ij}}{ }^{\mathrm{Min}}=\{80,20,60,20,20,80,20,80,80,20,80,60,80,80,60,80,60,60\}$

$\mathrm{X}_{\mathrm{ij}} \operatorname{Min}=20$

$\mathrm{R}_{11}=\frac{[[80-80]]}{[[80-20]]}$

$\mathrm{R}_{11}=\frac{0}{69}=0$

2. Hitung perbedaan evaluatif alternatif terhadap alternatif lainnya. Langkah ini melibatkan perhitungan perbedaan nilai kriteria antara alternatif pasangan yang berbeda.

3. Selanjutnya, fungsi preferensi dihitung untuk semua pasangan alternatif. menggunakan rumus (3) dan rumus (4).

Menghitung fungsi preferensi, $\mathrm{Pj}$ (i, i ').

$P_{j}(i, i)=0$ if $R_{i j} \leq R_{i}^{s} j$

$P_{j}(i, i)=\left(R i j-R_{i j j}\right)$ jika $R_{i j}>R_{i j j}$

Menghitung Nilai Kriteria Pekerjaan (C1)

$$
\begin{aligned}
\mathrm{C} 1(\mathrm{~A} 1, \mathrm{~A} 2): \mathrm{d} & =\mathrm{C} 1(\mathrm{~A} 1)-\mathrm{C} 1(\mathrm{~A} 2) \\
& =1-0 \\
& =1 \\
\mathrm{~d} & >0 \text { maka } \mathrm{H}|\mathrm{d}|=1
\end{aligned}
$$


4. Hitung fungsi preferensi agregat dengan mempertimbangkan bobot kriteria.Fungsi preferensi agregat. Dimana w j adalah kriteria kepentingan relatif (berat) dari jth.

$\pi\left(i, i^{\prime}\right)=\frac{\left[\sum_{j=1}^{m} w_{j} x P_{j}(i, i)\right]}{\sum_{j-1}^{m} w_{j}}$

Menghitung Indeks Preferensi

Alternatif pasangan $(\mathrm{A} 1, \mathrm{~A} 2)$

$$
\begin{aligned}
& (A 1, A 2)=\frac{[(20 \times 1)+(20 \times 0)+(10 \times 0,5)+(15 \times 1)+(1 \times 0)+(20 \times 0,7]]}{100} \\
& (\mathrm{~A} 1, \mathrm{~A} 2)=\frac{54}{100}=0,530
\end{aligned}
$$

\begin{tabular}{|c|c|c|c|c|c|c|c|c|c|c|c|c|c|c|c|c|c|c|c|}
\hline Alt & A1 & $\begin{array}{l}\text { A2 } \\
\end{array}$ & A3 & A4 & $\begin{array}{l}\text { A5 } \\
\end{array}$ & $\begin{array}{l}\text { A6 } \\
\end{array}$ & $\begin{array}{l}\text { A7 } \\
\end{array}$ & $\begin{array}{l}\text { A8 } \\
\end{array}$ & $\begin{array}{l}\text { A9 } \\
\end{array}$ & A10 & A11 & A12 & A13 & A14 & A15 & A16 & A17 & A18 & Total \\
\hline A1 & & 0,530 & 0,200 & 0,530 & 0,600 & 0,140 & 0,580 & 0,070 & 0,070 & 0,600 & 0,120 & 0,210 & 0,140 & 0,070 & 0,260 & 0,080 & 0,070 & 0,120 & 4,390 \\
\hline $\mathrm{A} 2$ & 0,250 & & 0,130 & 0,100 & 0,170 & 0,200 & 0,100 & 0,200 & 0,200 & 0,170 & 0,300 & 0,130 & 0,200 & 0,200 & 0,230 & 0,200 & 0,130 & 0,230 & 3,140 \\
\hline A3 & 0,120 & 0,330 & & 0,380 & 0,450 & 0,450 & 0,430 & 0,070 & 0,070 & 0,450 & 0,170 & 0,080 & 0,140 & 0,070 & 0,180 & 0,140 & 0,000 & 0,100 & 3,630 \\
\hline $\mathrm{A4}$ & 0,200 & 0,050 & 0,130 & & 0,070 & 0,200 & 0,050 & 0,200 & 0,200 & 0,070 & 0,200 & 0,130 & 0,200 & 0,200 & 0,130 & 0,200 & 0,130 & 0,130 & 2,490 \\
\hline A5 & 0,250 & 0,100 & 0,180 & 0,050 & & 0,250 & 0,100 & 0,200 & 0,200 & 0,000 & 0,200 & 0,130 & 0,200 & 0,250 & 0,180 & 0,250 & 0,130 & 0,130 & 2,800 \\
\hline A6 & 0,100 & 0,440 & 0,180 & 0,490 & 0,560 & & 0,540 & 0,054 & 0,050 & 0,560 & 0,150 & 0,120 & 0,000 & 0,050 & 0,220 & 0,050 & 0,050 & 0,150 & 3,764 \\
\hline A7 & 0,200 & 0,000 & 0,130 & 0,000 & 0,070 & 0,200 & & 0,200 & 0,200 & 0,070 & 0,200 & 0,130 & 0,200 & 0,200 & 0,130 & 0,200 & 0,130 & 0,130 & 2,390 \\
\hline A8 & 0,100 & 0,520 & 0,180 & 0,570 & 0,580 & 0,130 & 0,620 & & 0,000 & 0,580 & 0,100 & 0,140 & 0,080 & 0,050 & 0,290 & 0,130 & 0,000 & 0,100 & 4,170 \\
\hline A9 & 0,100 & 0,520 & 0,180 & 0,570 & 0,580 & 0,130 & 0,620 & 0,000 & & 0,550 & 0,100 & 0,140 & 0,080 & 0,050 & 0,290 & 0,130 & 0,000 & 0,100 & 4,140 \\
\hline A10 & 0,250 & 0,100 & 0,180 & 0,050 & 0,000 & 0,250 & 0,100 & 0,200 & 0,200 & & 0,200 & 0,130 & 0,200 & 0,250 & 0,180 & 0,250 & 0,130 & 0,130 & 2,800 \\
\hline A11 & 0,050 & 0,520 & 0,180 & 0,470 & 0,480 & 0,130 & 0,520 & 0,000 & 0,000 & 0,480 & & 0,140 & 0,080 & 0,050 & 0,190 & 0,130 & 0,000 & 0,000 & 3,420 \\
\hline$\overline{\mathrm{A12}}$ & 0,170 & 0,380 & 0,120 & 0,430 & 0,440 & 0,120 & 0,480 & 0,070 & 0,070 & 0,440 & 0,170 & & 0,070 & 0,120 & 0,220 & 0,120 & 0,000 & 0,100 & 3,520 \\
\hline A13 & 0,150 & 0,490 & 0,230 & 0,540 & 0,560 & 0,050 & 0,590 & 0,050 & 0,050 & 0,560 & 0,150 & 0,120 & & 0,100 & 0,270 & 0,100 & 0,050 & 0,150 & 4,210 \\
\hline A14 & 0,050 & 0,470 & 0,130 & 0,520 & 0,580 & 0,080 & 0,570 & 0,000 & 0,000 & 0,580 & 0,100 & 0,140 & 0,080 & & 0,240 & 0,080 & 0,000 & 0,100 & 3,720 \\
\hline A15 & 0,070 & 0,030 & 0,070 & 0,280 & 0,340 & 0,070 & 0,330 & 0,070 & 0,070 & 0,340 & 0,070 & 0,070 & 0,070 & 0,070 & & 0,070 & 0,000 & 0,000 & 2,020 \\
\hline A16 & 0,050 & 0,460 & 0,200 & 0,510 & 0,580 & 0,070 & 0,560 & 0,070 & 0,070 & 0,580 & 0,170 & 0,130 & 0,070 & 0,070 & 0,230 & & 0,070 & 0,170 & 4,060 \\
\hline A17 & 0,170 & 0,520 & 0,180 & 0,570 & 0,580 & 0,190 & 0,620 & 0,070 & 0,070 & 0,580 & 0,170 & 0,140 & 0,140 & 0,120 & 0,290 & 0,190 & & 0,100 & 4,700 \\
\hline A18 & 0,120 & 0,520 & 0,180 & 0,470 & 0,480 & 0,190 & 0,520 & 0,070 & 0,070 & 0,480 & 0,070 & 0,140 & 0,140 & 0,120 & 0,190 & 0,190 & 0,000 & & 3,950 \\
\hline Total & 2,400 & 5,980 & 2,7 & 6,530 & 7,120 & 2850 & 7,330 & 1,594 & 1,590 & 7,090 & 2,640 & 2,220 & 2,090 & 3,720 & 3,270 & 2,510 & 0,890 & 1,940 & \\
\hline
\end{tabular}

Tabel 11. Tabel Preferensi Agregat

5. Tentukan arus keluar dan arus outranking aliran (atau positif) arus (atau negatif) Dimana n adalah jumlah alternatif. Di sini, setiap alternatif menghadapi (n - 1) sejumlah alternatif lainnya. Menghitung Rumus aliran positif (Leaving Flow)

$$
\begin{aligned}
& \varphi^{+}(\mathrm{i})=\frac{1}{n-1} \sum_{i} n=\pi\left(\mathrm{i}, \mathrm{i}^{\prime}\right) \quad\left(\mathrm{i} \neq \mathrm{i}^{\prime}\right) \\
& \mathrm{A} 1=\frac{1}{18-1} * 4,39=0,258
\end{aligned}
$$

Tabel 12. Nilai Hasil Rangking

\begin{tabular}{|c|c|c|}
\hline Alternatif & Net Flow & Rangking \\
\hline A1 & 0,117 & 6 \\
\hline A2 & $-0,167$ & 14 \\
\hline A3 & 0,050 & 11 \\
\hline A4 & $-0,238$ & 15 \\
\hline A5 & $-0,254$ & 17 \\
\hline A6 & 0,054 & 10 \\
\hline A7 & 0,3 & 18 \\
\hline A8 & 0,152 & 2 \\
\hline A9 & 0,150 & 3 \\
\hline A10 & $-0,252$ & 16 \\
\hline A11 & 0,046 & 12 \\
\hline A12 & 0,076 & 9 \\
\hline A13 & 0,125 & 4 \\
\hline A14 & 0,099 & 7 \\
\hline A15 & $-0,100$ & 13 \\
\hline A16 & 0,091 & 8 \\
\hline \multicolumn{2}{|c|}{}
\end{tabular}




\begin{tabular}{|c|c|c|}
\hline Alternatif & Net Flow & Rangking \\
\hline A17 & 0,224 & 1 \\
\hline A18 & 0,118 & 5 \\
\hline
\end{tabular}

\section{HASIL DAN PEMBAHASAN}

\subsection{Hasil}

Pada bab ini penulis akan menguraikan hasil penelitian yang telah dilakukan yang berisikan tampilan eksekuisi atau implementasi dari sistem yang telah dibuat. Berikut adalah tampilan hasil dari implementasi perhitungan manual.

\subsubsection{Implementasi Algoritma Metode Promethee}

Pada bagian ini berisi tampilan sistem dengan menggunakan algoritma promethee. Berikut antaranya :

1. Data Alternatif merupakan data yang diambil dari kantor yang direkomendasikan menjadi seorang penerimaan bantuan tersebut.

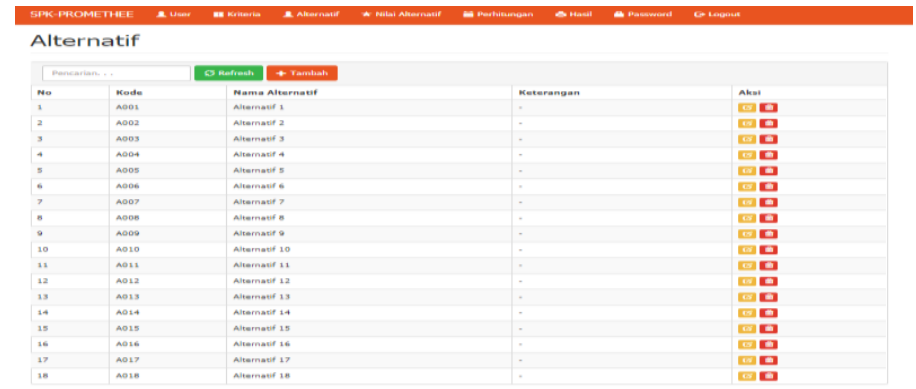

Gambar 2. Tampilan Daftar Alternatif

\subsubsection{Hasil Perangkingan}

Setelah pemberian nilai maka sistem akan memproses hasil sistem seperti apa yang dilihat pada gambar 4.7. adalah sebagai berikut .

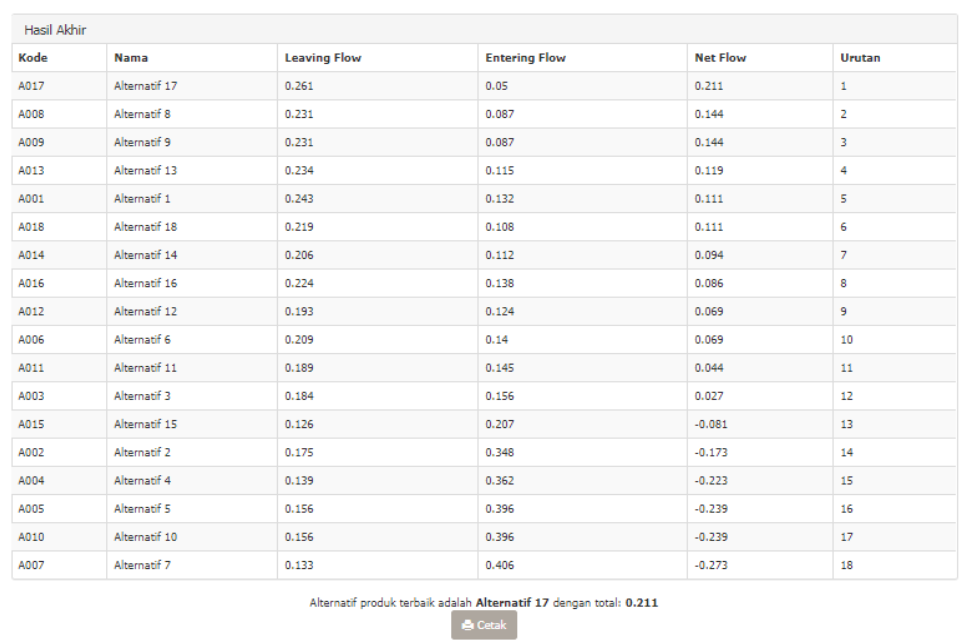

Gambar 3. Tampilan Hasil Perhitungan 


\subsection{Pembahasan}

Pengujian perhitungan manual yang diimplementasikan kedalam bentuk komputerisasi bertujuan untuk melihat kesesuaian hasil yang dieproleh antara perhitungan manual maupun secara komputerisasi. Jika hasil yang diperoleh menggunakan komputerisasi sesuai dengan perhitungan manual, maka kedepannya sistem yang dibangun mampu beroperasi di kantor terkait guna memebantu proses penentuan kelayakan penerimaan dana bantuan tersebut.

\section{KESIMPULAN}

Berdasarkan hasil perhitungan dan pembahasan Metode Promethee II dan implementasi pada bab sebelumnya, penulis dapat menarik kesimpulan sebagai berikut.

a. Metode Promethee II dapat diterapkan dengan baik pada Sistem Pendukung Keputusan (SPK) dalam pemilihan yang mendapat dana bantuan tersebut di masyarakat.

b. Data yang sebelumnya diolah dalam metode Promethee II telah diiplementasikan kedalam sistem komputerisasi yang bertujuan untuk membuktikan hasilnya sama dengan perhitungan manual pada metode Promethee II.

c. Hasil yang diperoleh dengan menggunakan metode Promethee II dapat melakukan perhitungan secara otomatis ketika pengguna menginputkan nilai kriteria, sehingga dapat mengurangi masalah dalam pengambilan keputusan kepada calon penerimaan dana bantuan di kantor.

d. Peneliti memberikan usulan untuk prioritaskan penerimaan dana bantuan agar tepat sasaran dan dapat membantu masyarakat yang kurang mampu dalam pengambilan keputusan. Berdasarkan hasil analisis peneliti dapat menyelesaikan masalah dalam penentuan penerimaan dana bantuan kepada masyarakat dengan baik dalam pengambilan keputusan.

\section{DAFTAR PUSTAKA}

[1] R. A. Hutasoit, S. Solikhun, and A. Wanto, "Analisa Pemilihan Barista dengan Menggunakan Metode TOPSIS (Studi Kasus: Mo Coffee)," KOMIK (Konferensi Nasional Teknologi Informasi dan Komputer), vol. 2, no. 1, pp. 256-262, 2018.

[2] T. Imandasari, A. Wanto, and A. P. Windarto, "Analisis Pengambilan Keputusan Dalam Menentukan Mahasiswa PKL Menggunakan Metode PROMETHEE," Jurnal Riset Komputer (JURIKOM), vol. 5, no. 3, pp. 234-239, 2018.

[3] M. Masitha, D. Hartama, and A. Wanto, "Analisa Metode (AHP) pada Pembelian Sepatu Sekolah Berdasarkan Konsumen," Seminar Nasional Sains \& Teknologi Informasi (SENSASI), vol. 1, no. 1, pp. 338-342, 2018.

[4] S. R. Ningsih, D. Hartama, A. Wanto, I. Parlina, and Solikhun, "Penerapan Sistem Pendukung Keputusan Pada Pemilihan Objek Wisata di Simalungun," in Seminar Nasional Teknologi Komputer \& Sains (SAINTEKS), 2019, pp. 731-735.

[5] L. P. Purba, A. P. Windarto, and A. Wanto, "Faktor Terbesar Rendahnya Minat Ber-KB (Keluarga Berencana) dengan Metode ELECTRE II," Seminar Nasional Sains \& Teknologi Informasi (SENSASI), vol. 1, no. 1, pp. 369-374, 2018.

[6] N. Rofiqo, A. P. Windarto, and A. Wanto, "Penerapan Metode VIKOR Pada Faktor Penyebab Rendahnya Minat Mahasiswa Dalam Menulis Artikel Ilmiah," Seminar Nasional Sains \& Teknologi Informasi (SENSASI), vol. 1, no. 1, pp. 228-237, 2018.

[7] S. Sundari, S. M. Sinaga, I. S. Damanik, and A. Wanto, "Sistem Pendukung Keputusan 
Pemilihan Peserta Olimpiade Matematika SMA Swasta Teladan Pematangsiantar Dengan Metode Electre," in Seminar Nasional Teknologi Komputer \& Sains (SAINTEKS), 2019, pp. 793-799.

[8] S. Sundari, A. Wanto, Saifullah, and I. Gunawan, "Sistem Pendukung Keputusan Dengan Menggunakan Metode Electre Dalam Merekomendasikan Dosen Berprestasi Bidang Ilmu Komputer (Study Kasus di AMIK \& STIKOM Tunas Bangsa)," in Seminar Nasional Multi Disiplin Ilmu, 2017, pp. 1-6.

[9] A. Wanto and H. Damanik, "Analisis Penerapan Sistem Pendukung Keputusan Terhadap Seleksi Penerima Beasiswa BBM (Bantuan Belajar Mahasiswa) Pada Perguruan Tinggi Menggunakan Metode Simple Additive Weighting (SAW) (Studi Kasus : AMIK Tunas Bangsa Pematangsiantar)," in Seminar Nasional Rekayasa (SNTR) II, 2015, no. 2, pp. 323-333.

[10] A. Wanto and E. Kurniawan, "Seleksi Penerimaan Asisten Laboratorium Menggunakan Algoritma AHP Pada AMIK-STIKOM Tunas Bangsa Pematangsiantar," Jurnal Informatika dan Komputer (JIKO), vol. 3, no. 1, pp. 11-18, 2018.

[11] M. Widyasuti, A. Wanto, D. Hartama, and E. Purwanto, "Rekomendasi Penjualan Aksesoris Handphone Menggunakan Metode Analitycal Hierarchy Process (AHP)," Konferensi Nasional Teknologi Informasi dan Komputer, vol. 1, no. 1, pp. 27-32, 2017.

[12] A. S. Sari, J. Nangi, and R. Ramadhan, “Penerapan metode,” vol. 2, no. 2, pp. 157-166, 2016.

[13] P. Studi, K. Dinas, L. Provinsi, and J. Timur, "Implementasi Metode Promethee II untuk Menentukan Pemenang Tender Implementasi Metode Promethee II untuk Menentukan Pemenang Tender Proyek ( Studi Kasus : Dinas Perhubungan dan LLAJ Provinsi Jawa Timur )," no. July 2017, 2018.

[14] I. S. Mesran, Pristiwanto, "Implementasi promethee ii dalam pemilihan pestisida terbaik untuk perawatan daun pada tanaman cabe," CESS (Journal of Computer Engineering System and Science), vol. 3, no. 2, pp. 139-146, 2018.

[15] A. P. U. Siahaan, A. D. Pradana, I. W. Sinaga, and M. Syahrial, "Sistem Pendukung Keputusan Pemilihan Bibit Kelapa Sawit Menerapkan Metode Promethee II," Seminar Nasional Sains \& Teknologi Informasi (SENSASI), pp. 472-483, 2018. 